\title{
A computational study on multiple formaldehyde complexes and their possible chemical reactions as well as the catalytic effect in the gas phase
}

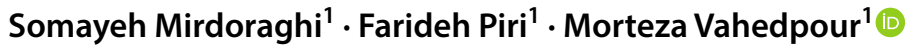

Received: 21 October 2019 / Accepted: 6 March 2020 / Published online: 12 March 2020

(c) Springer Nature Switzerland AG 2020

\begin{abstract}
A theoretical investigation on the dimerization and trimerization of formaldehyde molecules has focused on the singlet potential energy surface. Based on the possible reaction pathways, twelve transition states, three intermediates, and eight final products are obtained. All of the stationary points structures are calculated at the DFT/B3LYP method with the 6-311++G (3df, 3pd) basis set. In the present study, the CCSD/6-311++G (3df, 3pd) level of calculations was used to determine the precise energies of all species in the single point format on the B3LYP method optimized structures. The thermodynamic parameters were obtained using the DFT method. Our results show that among the obtained adducts six adducts have negative values in the Gibbs free energy. Also, the catalytic effect of formaldehyde was explored in the formation of 2-hydroxyacetaldehyde.
\end{abstract}

Keywords Catalytic effect $\cdot$ Multiple formaldehyde complexes $\cdot$ Reaction mechanism $\cdot$ Theoretical study

\section{Introduction}

Understanding and controlling intermolecular interactions play a crucial role in molecular recognition $[1,2]$, crystal engineering [3-6] and biological systems [7, 8]. Describing the interactions in molecular systems usually involves interpreting their geometry $[9,10]$ and overall energy [11]. The nature of intramolecular cooperative effects between atoms of molecules helps us to understand the origin of molecular association. For instance, hydrogen bonds and other noncovalent interactions have an important role in the stabilization of bimolecular structures such as proteins and nucleic acids $[12,13]$. In recent years, the interactions between $\mathrm{H}_{2} \mathrm{CO}$ molecules have been investigated both experimentally and theoretically [14]. These interactions lead to changes in the structure and shifting of IR spectra.
Theoretical studies can complete experimental researches about characterizing of origin of inter- and intramolecular interactions [15]. Deshmukh et al. [16] employed a DFT method to determine the interactions in linear formaldehyde oligomers, and they found that there are strong interactions between these chemicals. Dolgonos proposed a good level on the basis of the $\operatorname{CCSD}(T)$ method for investigating the isomers of formaldehyde $\left(C_{s}, C_{2 h}\right)$ interactions. Also, they had calculated zero-point energy (ZPE) and anharmonic correction. It was found that the dimer conformer with the $C_{s}$ symmetry is the true global minimum structure [17].

In this paper, some calculations have been done to study the dimmer and trimmer complexes of formaldehyde, and in the next step, their possible reaction pathways have been evaluated in the gas phase. To our knowledge,

Electronic supplementary material The online version of this article (https://doi.org/10.1007/s42452-020-2443-7) contains supplementary material, which is available to authorized users.

Morteza Vahedpour, vahed@znu.ac.ir | 'Department of Chemistry, University of Zanjan, P.O. Box 45371-38791, Zanjan, Iran. 
none of the following reactions considered here have been experimentally and theoretically characterized.

$$
\begin{aligned}
& \text { (1) } \mathrm{H}_{2} \mathrm{CO}+\mathrm{H}_{2} \mathrm{CO} \rightarrow \mathrm{C} 1 \rightarrow \mathrm{TS} 1 \rightarrow \mathrm{P} 1 \\
& \text { (2) } \mathrm{H}_{2} \mathrm{CO}+\mathrm{H}_{2} \mathrm{CO} \rightarrow \mathrm{C} 1 \rightarrow \mathrm{TS} 2 \rightarrow \mathrm{P} 1 \\
& \text { (3) } \mathrm{H}_{2} \mathrm{CO}+\mathrm{H}_{2} \mathrm{CO} \rightarrow \mathrm{C} 1 \rightarrow \mathrm{TS} 3 \rightarrow \mathrm{P} 3(1) \\
& \text { (4) } \mathrm{H}_{2} \mathrm{CO}+\mathrm{H}_{2} \mathrm{CO} \rightarrow \mathrm{C} 1 \rightarrow \mathrm{TS} 4 \rightarrow \mathrm{INT} 1 \rightarrow \mathrm{TS} 5 \rightarrow \mathrm{P} 3(2) \\
& (5) \mathrm{H}_{2} \mathrm{CO}+\mathrm{H}_{2} \mathrm{CO} \rightarrow \mathrm{C} 1 \rightarrow \mathrm{TS} 6 \rightarrow \mathrm{INT} 2 \rightarrow \mathrm{TS} 7 \rightarrow \mathrm{P} 4 \\
& \text { (6) } \mathrm{H}_{2} \mathrm{CO} \ldots \mathrm{H}_{2} \mathrm{CO}+\mathrm{H}_{2} \mathrm{CO} \rightarrow \mathrm{C} 3 \rightarrow \mathrm{TS} 8 \rightarrow \mathrm{INT} 3 \rightarrow \mathrm{TS} 9 \rightarrow \mathrm{P} 5 \\
& (7) \mathrm{H}_{2} \mathrm{CO} \ldots \mathrm{H}_{2} \mathrm{CO}+\mathrm{H}_{2} \mathrm{CO} \rightarrow \mathrm{C} 4 \rightarrow \mathrm{TS} 10 \rightarrow \mathrm{P} 6 \\
& \text { (8) } \mathrm{H}_{2} \mathrm{CO} \ldots \mathrm{H}_{2} \mathrm{CO}+\mathrm{H}_{2} \mathrm{CO} \rightarrow \mathrm{C} 5 \rightarrow \mathrm{TS} 11 \rightarrow \mathrm{P} 7 \\
& \text { (9) } \mathrm{H}_{2} \mathrm{CO} \ldots \mathrm{H}_{2} \mathrm{CO}+\mathrm{H}_{2} \mathrm{CO} \rightarrow \mathrm{C} 6 \rightarrow \mathrm{TS} 12 \rightarrow \mathrm{P} 8
\end{aligned}
$$

So, the novelty of this research is the discovering of new multiple formaldehyde complexes and evaluates their possible reactions. Moreover, to examine the formation of 2-hydroxyacetaldehyde, the catalytic feature of formaldehyde was investigated through DFT calculations at the B3LYP/6 311++G (3df, 3pd) level of computation.

\subsection{Calculation methods}

All calculations were performed using the popular method of density functional theory (DFT). The exchange part of this method is the Becke three-parameter hybrid functional (B3) [18] and the correlation part is the Lee-Yang-Parr (LYP) correlation [19] which was named the B3LYP method. The B3LYP method along with the $6-311++G(3 d f, 3 p d)$ basis set was implemented for geometry optimization. The Gaussian 09 program was used for all electronic structure calculations by using a personal computer [20]. Initially, all of the structures were optimized and vibrational frequencies were calculated at the B3LYP/6-311++G (3df, 3pd) level. If vibration analysis showed a negative frequency, the structure was assumed to refer to the transition state. On the other hand, the molecules would be characterized as minimum structure if no imaginary vibrational frequency was detected. The intrinsic reaction coordinate (IRC) calculation was applied to extract minimum energy paths from transition state structures and to determine the minimum structres of each transition state on the considered potential energy surface (PES) [21]. Also, total and relative energies were determined by the mentioned method above. Single point calculations were performed at the CCSD/6-311++G (3df, $3 p d)$ level to verify the accurate energies [22]. The counterpoise $(\mathrm{CP})$ procedure was used to control the interaction energy of basis set superposition error (BSSE) [23]. The results of the frequency analysis indicated that the ZPEs of all stationary points are small, but they have a significant effect on the relative energies. Hence, all energies were corrected by zero-point vibrational energies. The topological analyses were calculated with the Gaussian 09 program and visualized by the AIM2000 package program to obtain electronic charge densities and their Laplacian at bond critical points as well as ring critical points [24].

\section{Results and discussions}

The optimized structures of the reactants (R), complexes (C), transition states (TS), intermediates (INT), and products (P) are given in Figs. 1, 3, and 5. In this study, all of the reactions started with the production of a pre-reactive complex, which is represented by $C$ and followed by a number (C1-C6). The transition states here are specified with TS perfix and a number, consisting of TS1-TS12 and intermediates, are represented by INT perfix, including INT1-INT3. Finally, the products are denoted by P prefix, involving P1 until P8. For all reactions, PES schematics on the singlet state are drawn in Figs. 2, 4, and 6. Total energies and relative energies of all structures at the B3LYP method and single point energies at the CCSD method are presented in Table 1. The calculated vibrational frequencies of all species at the B3LYP/6-311+g (3df, 3pd) level are collected in Table $1 \mathrm{~S}$ in supplementary data. The formation processes for the P1, P2, P3 (1), and P3 (2) products are displayed in Scheme 1 , and the $\mathrm{P} 4$ and $\mathrm{P} 5$ products are shown in Scheme 2. Also, the formations of P6, P7, and P8 products are displayed in Scheme 3.

In this study, two pre-reactive complexes were obtained from the association of two formaldehyde molecules (C1-C2 complexes), and four others were taken from the assembly of three formaldehyde molecules (C3-C6 complexes). The complex formation between the original reactants was explored using the topological analysis of wave function obtained from the quantum theory of atoms in molecules (QTAIM). The Laplacian of the electronic charge density confirms the existing van der Waals and hydrogen bond interactions among the complexes fragments (Table 2). To produce a hydrogen bond, hydrogen atom number four, $\mathrm{H}(4)$, moves away from the first formaldehyde fragment and approaches to the $\mathrm{O}(7)$ atom of another formaldehyde fragment. Another van der Waals interaction was obtained when the $\mathrm{O}(1)$ atom of the first fragment approached to the $C(6)$ atom of another fragment to form the $\mathrm{C} 1$ complex. To the formation of the $\mathrm{C} 2$ complex, the $\mathrm{O}(1)$ atom of the first fragment approaches the $H(5)$ atom of the second fragment, and at the same time, the $\mathrm{O}(7)$ atom approaches to the $\mathrm{H}(4)$ atom. In the C3-C6 complexes, similar hydrogen bonds and van der Waals interactions are observed. All of the pre-reactive complexes are more stable than the original reactants. The relative stability of $\mathrm{C} 1-\mathrm{C} 6$ complexes are $-3.76,-3.14$, $-7.53,-7.53,-6.90$, and $-6.90 \mathrm{kcal} / \mathrm{mol}$ at the CCSD $/ 6$ $311++\mathrm{g}(3 \mathrm{df}, 3 \mathrm{pd})$ level, respectively. 
Fig. 1 The geometries of the reactants, products, intermediates, and transition states optimized at the B3LYP method (bond distances are in angstrom)

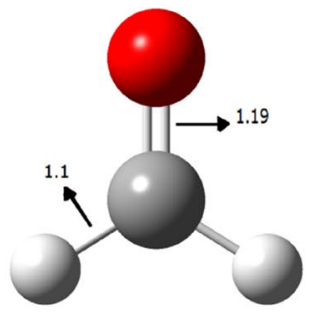

Formaldehyde

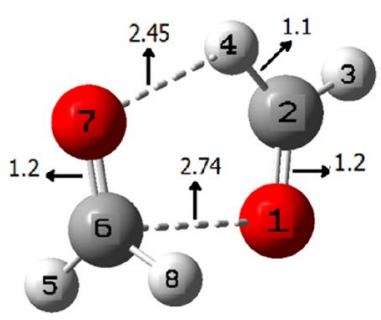

C1

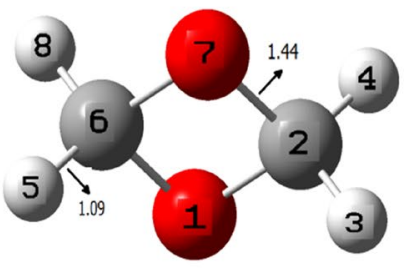

P1

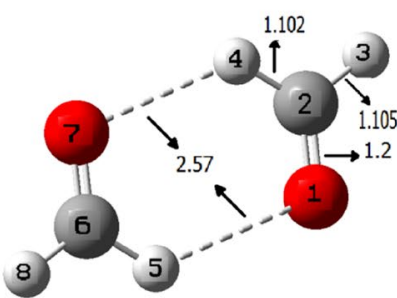

$\mathrm{C} 2$

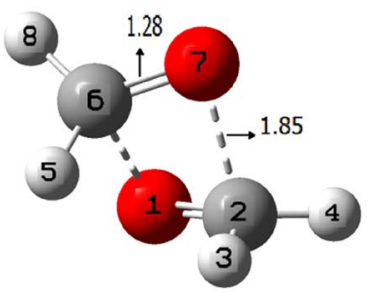

TS1

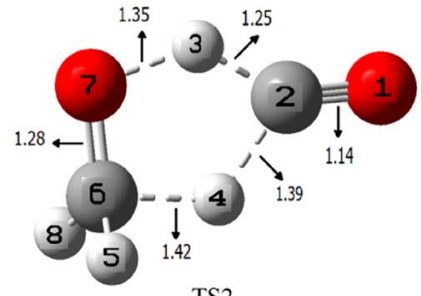

TS2
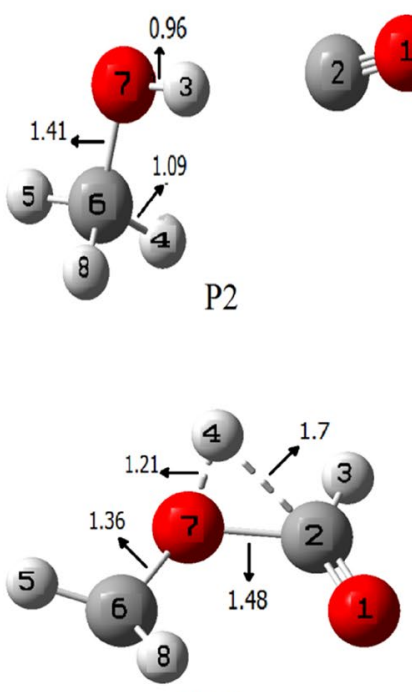

TS4
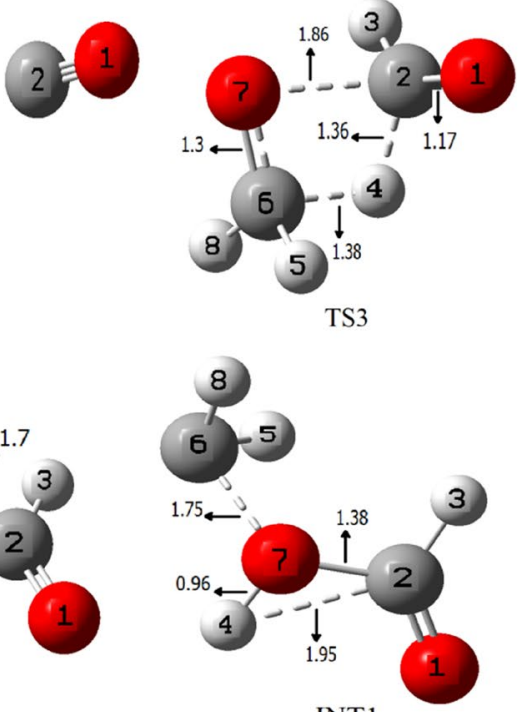

INT1
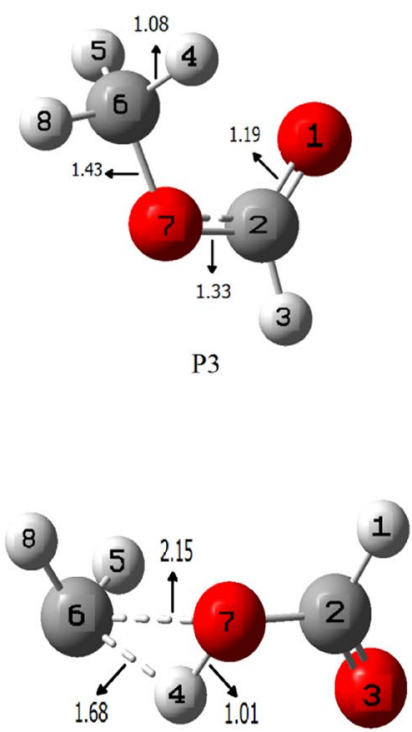

TS5

\subsection{P1 formation pathway}

The first possible pathway involves the concerted cycloaddition of carbonyl groups of two formaldehyde molecules that lead to 1,3-dioxetane. In path P1, the C1 complex undergoes $\mathrm{C}(2)-\mathrm{O}(7)$ and $\mathrm{O}(1)-\mathrm{C}(6)$ bond formations (Fig. 1). The geometry optimization of TS1 leads to the formation of a four-membered ring $(\mathrm{O}(1)-\mathrm{C}(6)-\mathrm{O}(7)-\mathrm{C}(2))$ structure. The energy barrier is $50.2 \mathrm{kcal} / \mathrm{mol}$ at the CCSD method to the conversion of the $\mathrm{C} 1$ to $\mathrm{P} 1$ with considering TS1. In the imaginary vibrational frequency mode, the $\mathrm{C}(2)$ atom approaches to the $\mathrm{O}(7)$ atom, and the $\mathrm{O}(1)$ atom close to the $C(6)$ atom, and at the same time, the structure of TS1 shows that the $\mathrm{C}-\mathrm{O}$ bonds of the formaldehyde fragments are weakening. As shown in Fig. 2, the P1 product is energetically $3.137 \mathrm{kcal} / \mathrm{mol}$ above the complex C1. $\mathrm{P} 1$ formation at room temperature is nonspontaneous.

\subsection{P2 formation pathway}

The C1 complex could directly transform into methanol and carbon monoxide. Disproportionation of the complex has occurred between two fragments in the $\mathrm{C} 1$ complex as a result of the transference of two hydrogen atom of a formaldehyde molecule to another. In path $\mathrm{P} 2$, the imaginary vibrational frequency of TS2 is $1583 \mathrm{i} \mathrm{cm}^{-1}$. Also, the 


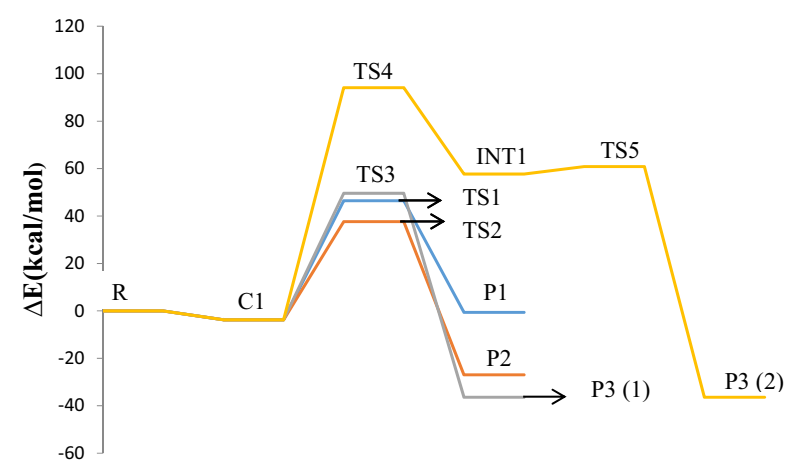

Fig. 2 Calculated energy profile for the suggested reaction paths for the $\mathrm{P} 1, \mathrm{P} 2, \mathrm{P} 3(1)$, and $\mathrm{P} 3(1)$ products at the $\mathrm{B} 3 \mathrm{LYP} / 6311++\mathrm{G}$ (3df, 3pd) level; the relative energy of the reactant $\mathrm{R}\left(\mathrm{H}_{2} \mathrm{CO}+\mathrm{H}_{2} \mathrm{CO}\right)$ is selected to zero as a reference point

geometry of this transiton state indicates the formation of a five-membered-ring $(\mathrm{C}(2)-\mathrm{H}(3)-\mathrm{O}(7)-\mathrm{C}(6)-\mathrm{H}(4))$. The energy barrier of TS2 is $41.415 \mathrm{kcal} / \mathrm{mol}$ at the CCSD/6$311++\mathrm{g}(3 \mathrm{df}, 3 \mathrm{pd})$ level. The imaginary vibrational frequency accompanied by IRC calculation show a simultaneous $\mathrm{H}(3)$ and $\mathrm{H}(4)$ hydrogen atoms shift from the $\mathrm{C}(2)$ and $\mathrm{O}(7)$ atoms to $\mathrm{C}(5)$ atom. The formation of $\mathrm{P} 2$ from the original reactants is spontaneous in thermodynamic terms. The energy barrier of TS2 shows the reaction is favorable kinetically (the activation free energy for this path is $32.42 \mathrm{kcal} / \mathrm{mol}$ ). The P2 adduct is $26.982 \mathrm{kcal} / \mathrm{mol}$ below than the original reactant.

\subsection{P3 formation pathway}

In this pathway, the $\mathrm{C} 1$ complex is rearranged to methyl format according to the intermolecular reaction via hydrogen atom transfer $(\mathrm{H}(4))$ from $\mathrm{C}(2)$ carbon atom to $\mathrm{C}(6)$ and at the same time, the oxygen atom $(\mathrm{O}(7))$ creates a bond with the carbon atom $(C(2))$, which whose $\mathrm{H}$ atom was abstracted. Consequently, an ester group is formed. There are two possible paths for P3 formation. In the first path, the path $\mathrm{P} 3(1)$, a four-membered ring $(\mathrm{C}(2)-\mathrm{O}(7)-\mathrm{C}(6)-\mathrm{H}(4))$ transition state (TS3) is formed with an energy barrier of $53.337 \mathrm{kcal} / \mathrm{mol}$ at the CCSD/6$311++g(3 \mathrm{df}, 3 \mathrm{pd})$ level of theory. The imaginary vibrational frequency of TS3 is $1153 \mathrm{i} \mathrm{cm}^{-1}$ in the reaction coordinate. The IRC computation along with the imaginary vibration mode for TS3 indicates that $\mathrm{H}(4)$ atom shifts from $C(2)$ atom to $C(6)$ atom and at the same time $C(2)$ atom approaches the $\mathrm{O}(7)$ atom. In the second path, the path $\mathrm{P} 3(2)$, the $\mathrm{C} 1$ complex converts to the INT1 intermediate by passing through a three-membered ring $(\mathrm{C}(2)-\mathrm{O}(7)-\mathrm{H} 4)$ ) transition state (TS4) with an energy barrier of $97.89 \mathrm{kcal} /$ mol at the CCSD method. The IRC calculation demonstrates that in the structure of TS4 $\mathrm{H}(4)$ atom shifts to $\mathrm{O}(7)$ atom and, $\mathrm{O}$ (7) atom approaches to $\mathrm{C}(2)$ atom. In the next step, the INT1 is transformed into P3 via the transition state TS5. Geometrically, this transition state has a three-membered ring structure $(\mathrm{C}(6)-\mathrm{O}(7)-4(\mathrm{H}))$ with an energy barrier of $3.137 \mathrm{kcal} / \mathrm{mol}$. The P3 adduct (2) is $94.125 \mathrm{kcal} / \mathrm{mol}$ more stable than the INT1 intermediate. The shifting of the $\mathrm{H}(4)$ atom to the $\mathrm{C}(6)$ atom and then, approaching of the $\mathrm{C}(6)$ atom to $\mathrm{O}(7)$ atom simultaneously is confirmed by IRC calculation. Not only, the P3 formation is thermodynamically spontaneous by both paths, but also it is kinetically favorable by the path P3(1). The P3 formation in the path P3(2) is unfavorable in the kinetic point of view in comparison with the $\mathrm{P} 3(1)$ path. The reaction energy profile for $\mathrm{P} 1$, P2, P3(1), and P3(2) paths are displayed in Fig. 2, and also these paths are schematized (see Scheme 1) as follows:

\subsection{The catalytic effect of formaldehyde on the P4 and P5 formation pathways}

In the path P4, 2-hydroxyacetaldehyde could be obtained by reaction of two formaldehyde molecules through a van der Waals complex formation (Fig. 3). In one formaldehyde 1,2-hydrogen shift can occur and then a C...C van der Waals interaction emerges along with hydrogen transfer from the $\mathrm{C}(2)$ atom to the $\mathrm{O}(1)$ atom. Form the $\mathrm{C} 1$ complex, the INT2 intermediate is produced by passing through TS6. In the structure of TS6, the $\mathrm{O}(1)-\mathrm{H}(4)$ bond is forming and the $2 \mathrm{C}-4 \mathrm{H}$ bond is breaking in a three-membered ring structure $(\mathrm{C}(2)-\mathrm{O}(1)-\mathrm{H}(4)$. The INT2 is $40.787 \mathrm{kcal} /$ mol above the original reactants. The TS6 energy barrier is $82.892 \mathrm{kcal} / \mathrm{mol}$ at the CCSD method. The IRC computation and also the imaginary (vibrational) frequency of TS6 approve the 1,2-hydrogen shift, in which the $\mathrm{H}(4)$ atom shifts from the $C(2)$ atom to the $\mathrm{O}(1)$ atom. In the next step of this path, the conversion of INT2 into the final adduct $\mathrm{P} 4$ is happened by sourmounting on a five-membered ring $(\mathrm{C}(2)-\mathrm{O}(1)-\mathrm{H}(4)-\mathrm{O}(7)-\mathrm{C}(6))$ transition state TS7 that has a low energy barrier (about $1.255 \mathrm{kcal} / \mathrm{mol}$ ) compared to its corresponding intermediate. The minimum energy path obtained by IRC calculation displays that the $C(2)$ atom closes to the $C(6)$ atom and, simultaneously, the $H(4)$ atom migrates to the $\mathrm{O}(7)$ atom. The $\mathrm{P} 4$ formation is thermodynamically spontaneous with a value of $8.53 \mathrm{kcal} / \mathrm{mol}$ in Gibbs free energy. Our calculations suggest that the P4 formation is kinetically unfavorable in comparison with the $\mathrm{P} 5$ formation.

\section{$2.5 \mathrm{H}_{2} \mathrm{CO} \ldots \mathrm{H}_{2} \mathrm{CO}+\mathrm{H}_{2} \mathrm{CO}$ reactions}

Association of three-formaldehyde-molecule in the C3 complex (see Fig. 3) could yield 2-(hydroxymethoxy) acetaldehyde. In the path $\mathrm{P} 5$, the $\mathrm{C} 3$ complex is converted into the INT3 intermediate by passing through a six-membered 
Fig. 3 The obtained geometries along the suggested reaction paths for $\mathrm{P} 4, \mathrm{P} 5$

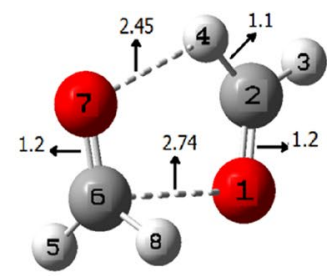

$\mathrm{C} 1$

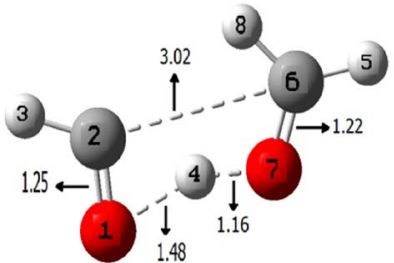

TS6

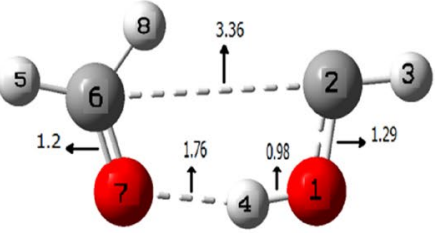

INT2

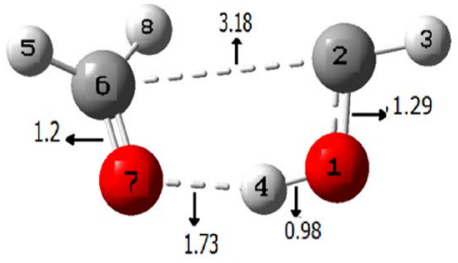

TS7
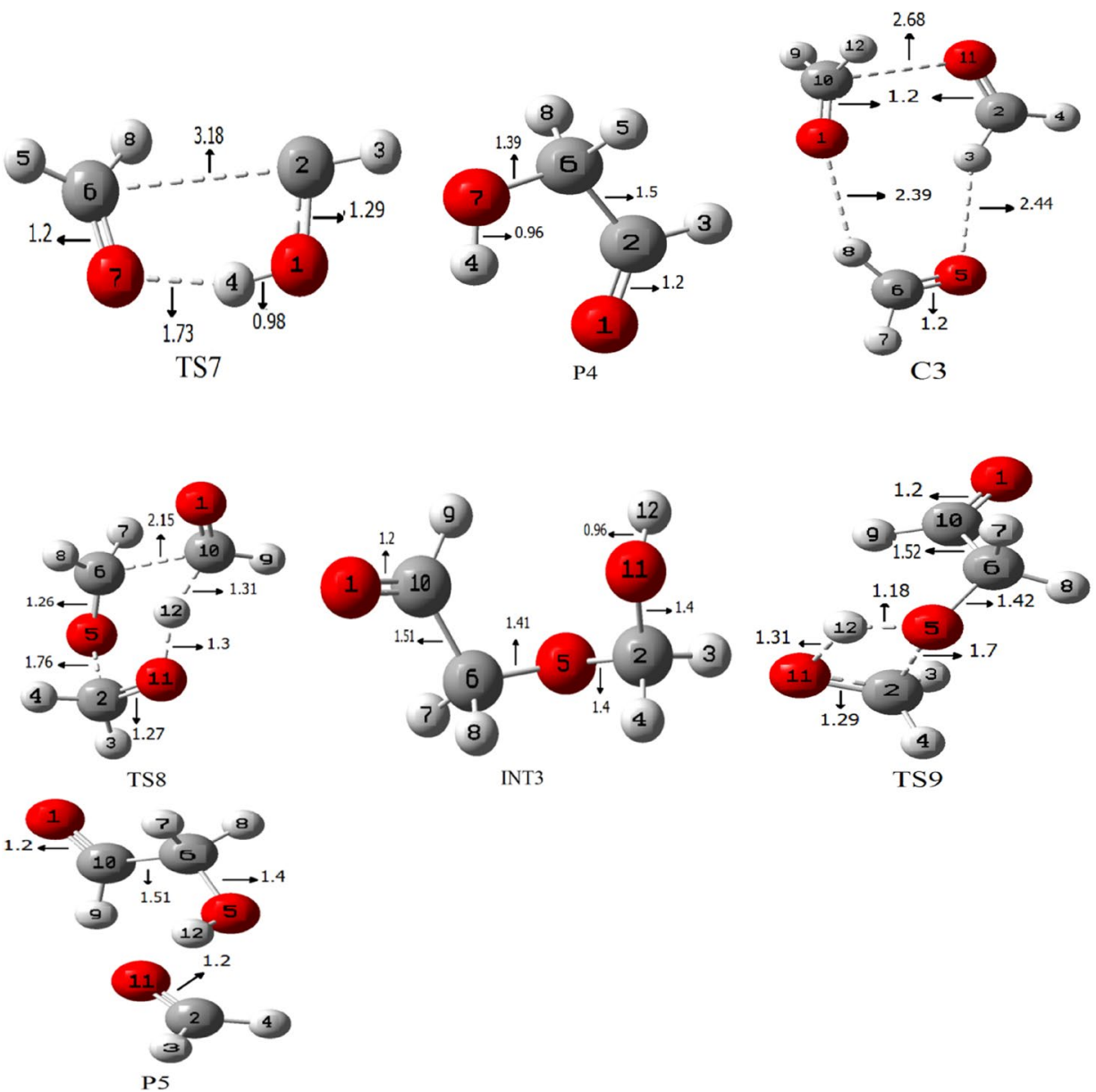

ring structure $(\mathrm{C}(6)-\mathrm{O}(5)-\mathrm{C}(2)-\mathrm{O}(11)-\mathrm{H}(12)-\mathrm{C}(10))$ transition state (TS8) with the energy barrier of $53.965 \mathrm{kcal} / \mathrm{mol}$ at the CCSD level. The structure of TS8 contains a nucleophilic attachment of the $\mathrm{O}(5)$ atom of the first formaldehyde to the $C(2)$ atom of the second. At the same time, the $\mathrm{H}(12)$ atom of the third fragment shifts to the $\mathrm{O}(11)$ atom of the second in order to form the carbon-carbon $C(6)-C(10)$ bond. The imaginary vibrational frequency of TS8 illustrates that $\mathrm{H}(12)$ atom shifting to $\mathrm{O}(5)$ atom and moving away from $\mathrm{O}(11)$ atom, leading to the formation of the $\mathrm{C}(6)-\mathrm{C}(10), \mathrm{C}(2)-\mathrm{O}(5)$, and $\mathrm{H}(11)-\mathrm{HO}(12)$, bonds. The IRC calculation confirms the mentioned process in TS8 and also show that the $\mathrm{H}(12)-\mathrm{C}(10)$ bond breaking, and the newly $\mathrm{O}(5)-\mathrm{C}(2), \mathrm{C}(6)-\mathrm{C}(10)$, and $\mathrm{O}(11)-\mathrm{H}(12)$ bonds forming, and then production of the INT3 intermediate. Finally, INT3 is converted to the P5 product by passing through a transition state with a four-membered ring structure $(\mathrm{C}(2)-\mathrm{O}(11)-\mathrm{H}(12)-\mathrm{O}(5))$ which is represented by TS9. The energy barrier of this transition state is $54.592 \mathrm{kcal} / \mathrm{mol}$ in comparison with its corresponding intermediate (INT3). The IRC calculation of TS9 shows the $\mathrm{H}(12)$ hydrogen atom transfers from the $\mathrm{O}(11)$ atom to the $\mathrm{O}(5)$ atom in the INT3. Then, one formaldehyde molecule can reproduce through TS9. The P5 product is energetically $11.922 \mathrm{kcal} / \mathrm{mol}$ more stable than the INT3. As shown in Fig. 4, the P5 pathway is most suitable for the preparation of 2-hydroxyacetaldehyde. The catalytic property of formaldehyde could be observed more clearly in this 
Table 1 Total (without ZPE correction) and relative energies including ZPE correction (in parentheses) of the reactants, products, and intermediates at the B3LYP/6$311++g(3 d f, 3 p d)$ and CCSD/6$311++\mathrm{g}(3 \mathrm{df}, 3 \mathrm{pd})$ levels

\begin{tabular}{|c|c|c|}
\hline Species & B3LYP & CCSD \\
\hline $\mathrm{R} 1(\mathrm{HCHO}+\mathrm{HCHO})$ & $-229.046(0.000)$ & $-228.638(0.000)$ \\
\hline $\mathrm{C} 1$ & $-229.048(-1.255)$ & $-228.644(-3.765)$ \\
\hline C2 & $-229.048(-1.255)$ & $-228.643(-3.137)$ \\
\hline TS1 & $-228.974(45.180)$ & $-228.564(46.435)$ \\
\hline P1 & $-229.030(10.04)$ & $-228.639(-0.627)$ \\
\hline TS2 & $-229.000(28.865)$ & $-228.578(37.65)$ \\
\hline P2 & $-229.075(-18.197)$ & $-228.681(-26.982)$ \\
\hline TS3 & $-228.978(42.67)$ & $-228.559(49.572)$ \\
\hline P3 & $-229.094(-30.12)$ & $-228.696(-36.395)$ \\
\hline TS4 & $-228.914(82.83)$ & $-228.488(94.125)$ \\
\hline Int1 & $-228.951(59.612)$ & $-228.546(57.73)$ \\
\hline TS5 & $-228.949(60.867)$ & $-228.541(60.867)$ \\
\hline TS6 & $-228.924(76.555)$ & $-228.512(79.065)$ \\
\hline INT2 & $-228.974(45.18)$ & $-228.573(40.787)$ \\
\hline TS7 & $-228.974(45.18)$ & $-228.571(42.042)$ \\
\hline P4 & $-229.077(-19.452)$ & $-228.680(-26.355)$ \\
\hline $\mathrm{R} 2(\mathrm{HCHO}+\mathrm{HCHO}+\mathrm{HCHO})$ & $-343.570(0.000)$ & $-342.957(0.000)$ \\
\hline $\mathrm{C} 3$ & $-343.575(-3.137)$ & $-342.969(-7.530)$ \\
\hline TS8 & $-343.504(41.415)$ & $-342.883(46.435)$ \\
\hline INT3 & $-343.609(-24.472)$ & $-343.022(-40.787)$ \\
\hline TS9 & $-343.539(19.452)$ & $-342.935(13.805)$ \\
\hline P5 & $-343.601(-19.452)$ & $-343.003(-28.865)$ \\
\hline C4 & $-343.575(-3.137)$ & $-342.969(-7.53)$ \\
\hline TS10 & $-343.538(20.08)$ & $-342.928(18.197)$ \\
\hline P6 & $-343.601(-19.452)$ & $-343.022(-40.787)$ \\
\hline C5 & $-343.574(-2.51)$ & $-342.968(-6.902)$ \\
\hline TS11 & $-343.522(30.120)$ & $-342.901(35.140)$ \\
\hline P7 & $-343.627(-35.767)$ & $-343.036(-49.572)$ \\
\hline C6 & $-343.575(-3.137)$ & $-342.968(-6.902)$ \\
\hline TS12 & $-343.499(44.552)$ & $-342.872(53.337)$ \\
\hline P8 & $-343.635(-40.787)$ & $-343.047(-56.475)$ \\
\hline
\end{tabular}

Total energies are in Hartree, and relative energies are in $\mathrm{kcal} / \mathrm{mol}$ reaction. Our calculations predict that the rate constant for the suggested mechanism of trimmer formaldehyde reaction is higher than the dimmer formaldehyde. Since the number of transition states is equal in the pathways of P4 and P5, we conclude that the barriers of the P5 path transition states are lower than the corresponding transition states for the P4 path. So, the generation of P5 product is more favorable than the $\mathrm{P} 4$ product kinetically. The energy levels of transition states confirm that the third formaldehyde molecule has catalyzer role in the reaction between two formaldehyde molecules. To form P4, a 1,2-hydrogen shift was occured. It is well-known, the activation energy for this rearrangement should be larger than that of in antiaromatic compounds [25], but in the P5 product formation, the nucleophilic attachments between the $\mathrm{O}(5)$ and $\mathrm{C}(2)$ atoms, and formation of the $\mathrm{O}(11)-\mathrm{H}(12)$ bond can cause to facilitate the $\mathrm{H}(12)$ hydrogen atom transfers from the $C(10)$ atom to the $\mathrm{O}(11)$. Meanwhile, a carbon-carbon bond is formed simultaneously. Finally, the main catalyst is regenerated as the final adduct in the P5 pathway. The energy profiles of the P4 and P5 products formation from the original reactants are shown in Fig. 4, and the investigated reactions are schematized in Scheme 2 as follows.

\subsection{P6 formation pathway}

1, 3, 5-trioxane could be synthesized via concerted cycloaddition from the ternary complex of formaldehyde. In the Path $\mathrm{P} 6$, the $\mathrm{C} 4$ complex undergoes the $\mathrm{O}(1)-\mathrm{C}(2), \mathrm{O}(5)-\mathrm{C}(9)$, and $\mathrm{O}(10)-\mathrm{C}(6)$ bonds formation. In the reaction coordinate, the imaginary vibrational frequency of transition state TS10 is $482 \mathrm{i} \mathrm{cm}{ }^{-1}$. Also, it has a six-membered ring structure among the $O(1), C(2), 5(0)$, 
Scheme 1 Process of $\mathrm{P} 1, \mathrm{P} 2$, P3(1), and P3(2) formation<smiles>O=CC=O</smiles><smiles></smiles><smiles>C1OCO1</smiles>

P1<smiles>C=O</smiles>

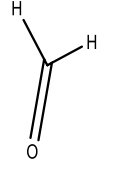

$\mathrm{Cl}$
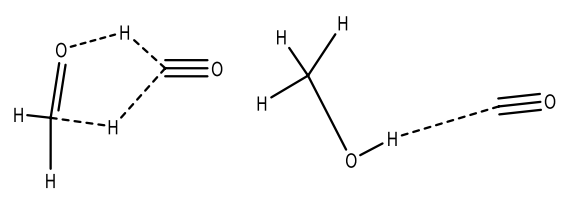

P2<smiles>C=O</smiles><smiles>C=O</smiles><smiles></smiles><smiles>COC=O</smiles>

$\mathrm{C} 1 \quad \longrightarrow \quad \mathrm{TS} 3 \quad \mathrm{P} 3(1)$

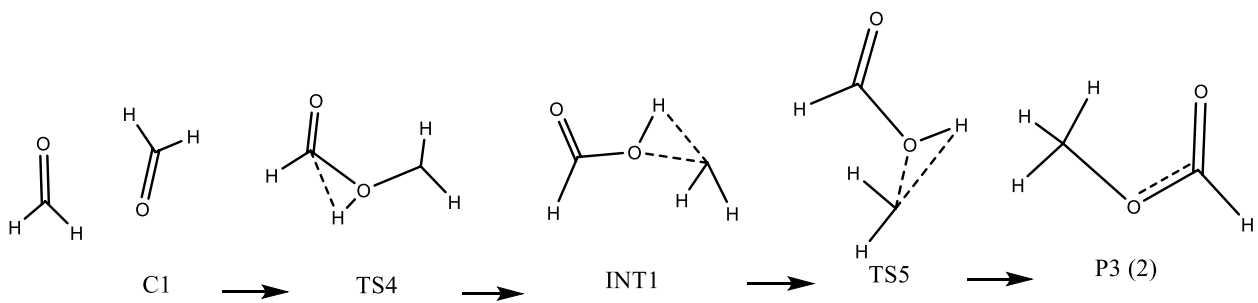

Scheme 2. Respective process of P4 and P5 formation<smiles>O=C=CO</smiles>

INT<smiles>O=CO</smiles>

C3

TS8<smiles>OCOC1CO1</smiles>

INT3<smiles>O=CCO</smiles><smiles>C=C=CI</smiles><smiles>C=O</smiles>

TS7<smiles>O=CCO</smiles><smiles>O=CCO</smiles><smiles>C=O</smiles>

P5
9(C), 10(O), and 6(C) atoms (see Fig. 5). The energy barrier of TS10 is $25.727 \mathrm{kcal} / \mathrm{mol}$ at the CCSD method. In this reaction, the $\mathrm{O}(10)$ atom approaches the $\mathrm{C}(6)$ atom, and at the same time, the $\mathrm{O}(1)$ and $\mathrm{O}(5)$ atoms approach the $C(2)$ and C(9) atoms, respectively. As the computed Gibbs free energy show, the P6 formation is spontaneous at room temperature. Also, the existence of one transition state with a suitable energy barrier indicates that the reaction path is kinetically favorable (the activation free energy for this path is $28.28 \mathrm{kcal} / \mathrm{mol}$ ).

\subsection{P7 formation pathway}

The three-formaldehyde-molecule complex could produce methoxymethyl formate via nucleophilic attachments of the $\mathrm{O}(3)$ atom of the first formaldehyde to the $\mathrm{C}(10)$ atom 


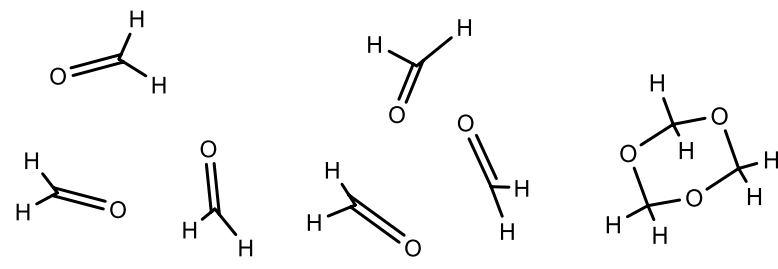

C4

TS10

$\longrightarrow \quad \mathrm{P} 6$

$\prod_{0}^{H}\left\|_{H}^{H}\right\|_{0}^{H}$

C5<smiles>[TeH][TeH]</smiles>

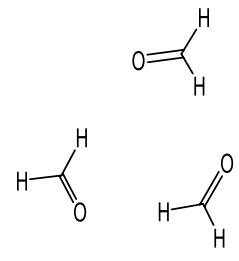

C6
TS11

$\longrightarrow \quad \mathrm{P} 7$
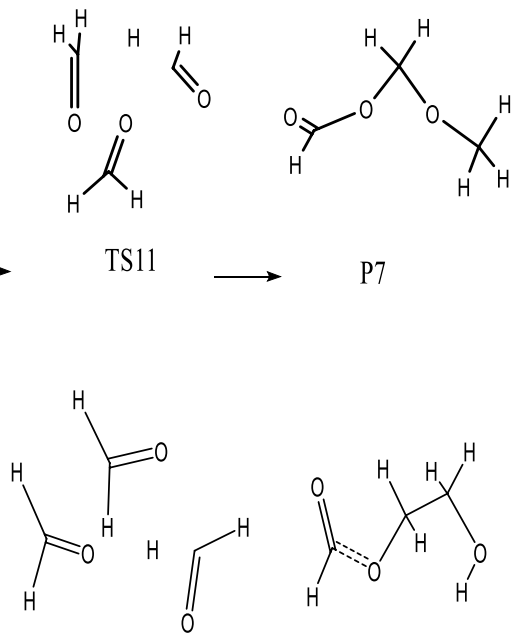

TS12

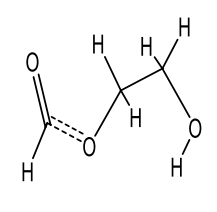

P8
Scheme 3 Respective process of the P6, P7 and, P8 formation

of the second, and the $\mathrm{O}(4)$ atom of the second to the $\mathrm{C}(2)$ atom of the third. At the same time, the $\mathrm{H}(12)$ of the third transfers from the $C(2)$ atom to the $C(7)$ atom of the first. In the path $\mathrm{P} 7$, the $\mathrm{C} 5$ complex undergoes methoxymethyl formate formation by passing through a six-memberedring structure $(\mathrm{C}(2)-\mathrm{H}(12)-\mathrm{C}(7)-\mathrm{O}(3)-\mathrm{C}(10)-\mathrm{O}(4))$ transition state (TS11). The energy barrier of TS1 1 is $42.042 \mathrm{kcal} /$ $\mathrm{mol}$ at the CCSD method. The imaginary vibrational frequency is $766 \mathrm{i} \mathrm{cm}^{-1}$. After IRC calculation, the obtained minimum structures show that the $\mathrm{O}(4)$ atom is bonded to the $C(2)$ atom and the $O(3)$ atom is linked to the $C(10)$ atom when the $\mathrm{H}(12)$ approaches the $\mathrm{C}(7)$ atom. The P7 product formation is thermodynamically spontaneous with a value of $14.76 \mathrm{kcal} / \mathrm{mol}$ in standard Gibbs free energy, and also it is kinetically favorable at $298.15 \mathrm{~K}$.

\subsection{P8 formation pathway}

In the path P8, the C6 complex is directly converted to 2-hydroxyethyl formate by passing through a six-membered-ring structure $(\mathrm{C}(8)-\mathrm{O}(5)-\mathrm{C}(9)-\mathrm{C}(6)-\mathrm{O}(10)-\mathrm{H}(12))$ transition state (TS12). At the CCSD/6-311++g (3df, 3pd) level of theory, the energy barrier and the imaginary vibrational frequency of TS12 are $60.239 \mathrm{kcal} / \mathrm{mol}$ and
$1188 \mathrm{i} \mathrm{cm}{ }^{-1}$ in the reaction coordinate, respectively. The relative energy of the $\mathrm{P} 8$ product is $49.573 \mathrm{kcal} / \mathrm{mol}$ lower than the $\mathrm{C} 6$ complex. The energy profile of the reaction pathway is shown in Fig. 6. In Scheme 3, the considered pathways of the P6, P7 and, P8 products are brought.

\subsection{Thermodynamic properties of reactions}

The gas phase thermodynamic parameters of the above mentioned adducts are listed at room temperature and atmospheric pressure in Table 3. Internal energies, enthalpies, Gibbs free energies, and entropies of all possible reactions were calculated at the B3LYP/6-311++g (3df, 3pd) level at the stated conditions. Enthalpies of the P1-P8 products are $8.01,-18.20,-31.34 .-20.48,-21.14,-23.90$, -38.52 , and $-43.79 \mathrm{kcal} / \mathrm{mol}$, respectively. In comparison with other products, the most exothermic reaction is the $\mathrm{P} 8$ adduct due to the formation of strong covalent bonds (such as $\mathrm{C}-\mathrm{C}$ ). The positive signs of $\Delta H^{\circ}$ for $\mathrm{P} 1$ and $\mathrm{P} 6$ reveal that their production is an endothermic process. The computed Gibbs free energies for the generation of the P2, P3, $\mathrm{P} 4, \mathrm{P} 5, \mathrm{P} 7$, and $\mathrm{P} 8$ products show that they are spontaneous reactions at standard conditions. Also, $T \Delta S^{\circ}$ is negative for all products due to the loss of some translational, rotational, and electronic degrees of freedom and the tight transition states.

In summery, the $\mathrm{P} 8$ product by $-19.89 \mathrm{kcal} / \mathrm{mol}$ in its $\Delta G^{\circ}$ and $-43.79 \mathrm{kcal} / \mathrm{mol}$ in its $\Delta H^{\circ}$ is thermodynamically the most favorable product. The thermodynamic character shows that the P1 formation path is endothermic under these conditions with $8.01 \mathrm{kcal} / \mathrm{mol}$. Furthermore, according to Gibbs free energy, it is a nonspontaneous reaction with $20.8 \mathrm{kcal} / \mathrm{mol}$. So, this reaction is thermodynamically unfavorable. The P6 production is exothermic with $23.9 \mathrm{kcal} / \mathrm{mol}$ and nonspontaneous with Gibbs free energy of $3.2 \mathrm{kcal} / \mathrm{mol}$ at these conditions. Overall, the results indicate that the P2, P3, P4, P5, P7, and P8 formation pathways are exothermic and spontaneous reactions in the gas phase and at atmospheric conditions.

In the kinetic point of view, our calculation proved the catalytic effect of formaldehyde molecule in the production of the P4 and P5 products. Also, on the basis of the obtained results, it is predictable that the production of the $\mathrm{P} 1, \mathrm{P} 2, \mathrm{P} 3, \mathrm{P} 6$, and $\mathrm{P} 7$ are feasible than the others.

\subsection{Comparison of the obtained dimer and trimer complexes with literature}

The electronic structures and spectra of formaldehyde dimers were studied by several researchers experimentally and theoretically $[1,2,17,26-28]$

Dornshuld et al. investigated the minima structures of formaldehyde and thioformaldehyde dimers such as 
Table 2 AIM analysis of all complexes

\begin{tabular}{|c|c|c|c|c|c|}
\hline \multirow[t]{2}{*}{ Complex } & \multicolumn{3}{|c|}{ Bond critical point } & \multicolumn{2}{|c|}{ Ring critical point } \\
\hline & & $\rho$ (bcp) e bohr ${ }^{-3}$ & $\begin{array}{l}\Delta^{2} \rho(\mathrm{bcp}) \text { e } \\
\text { bohr }^{-5}\end{array}$ & $\rho(\mathrm{rcp})$ e bohr ${ }^{-3}$ & $\begin{array}{l}\Delta^{2} \rho(\mathrm{rcp}) \\
\text { e bohr }\end{array}$ \\
\hline \multirow[t]{2}{*}{ C1 } & $70-4 \mathrm{H}$ & 0.009 & 0.032 & 0.007 & 0.036 \\
\hline & $6 C-10$ & 0.013 & 0.040 & & \\
\hline \multirow[t]{2}{*}{ C2 } & 70-4H & 0.008 & 0.024 & 0.003 & 0.020 \\
\hline & $10-5 \mathrm{H}$ & 0.008 & 0.024 & & \\
\hline \multirow[t]{4}{*}{ C3 } & $10 C-110$ & 0.014 & 0.036 & 0.002 & 0.008 \\
\hline & $3 \mathrm{H}-5 \mathrm{O}$ & 0.010 & 0.028 & 0.005 & 0.024 \\
\hline & $8 \mathrm{H}-10$ & 0.009 & 0.032 & & \\
\hline & $3 \mathrm{H}-10$ & 0.005 & 0.020 & & \\
\hline \multirow[t]{4}{*}{ C4 } & $10-2 \mathrm{C}$ & 0.010 & 0.036 & 0.002 & 0.008 \\
\hline & $8 \mathrm{H}-10 \mathrm{O}$ & 0.006 & 0.036 & 0.006 & 0.028 \\
\hline & $50-9 \mathrm{C}$ & 0.015 & 0.036 & & \\
\hline & $10 \mathrm{O}-4 \mathrm{H}$ & 0.009 & 0.028 & & \\
\hline \multirow[t]{4}{*}{ C5 } & $9 \mathrm{H}-4 \mathrm{O}$ & 0.008 & 0.024 & 0.007 & 0.032 \\
\hline & $6 \mathrm{O}-10 \mathrm{C}$ & 0.014 & 0.044 & 0.007 & 0.032 \\
\hline & $4 \mathrm{O}-2 \mathrm{C}$ & 0.013 & 0.044 & & \\
\hline & $11 \mathrm{H}-30$ & 0.008 & 0.028 & & \\
\hline \multirow[t]{3}{*}{ C6 } & $5 \mathrm{O}-3 \mathrm{H}$ & 0.01 & 0.032 & 0.0003 & 0.032 \\
\hline & $10 \mathrm{O}-12 \mathrm{H}$ & 0.01 & 0.032 & & \\
\hline & $10-4 \mathrm{H}$ & 0.01 & 0.032 & & \\
\hline \multirow[t]{4}{*}{ C7 } & $5 \mathrm{O}-4 \mathrm{H}$ & 0.009 & 0.032 & 0.007 & 0.036 \\
\hline & $5 \mathrm{O}-11 \mathrm{H}$ & 0.009 & 0.032 & 0.007 & 0.036 \\
\hline & $30-6 \mathrm{C}$ & 0.011 & 0.036 & & \\
\hline & $6 C-100$ & 0.011 & 0.036 & & \\
\hline
\end{tabular}

$\rho$ : electronic charge density of the wave function

$\Delta^{2} \rho$ : Laplacian of the electronic charge density at a critical point

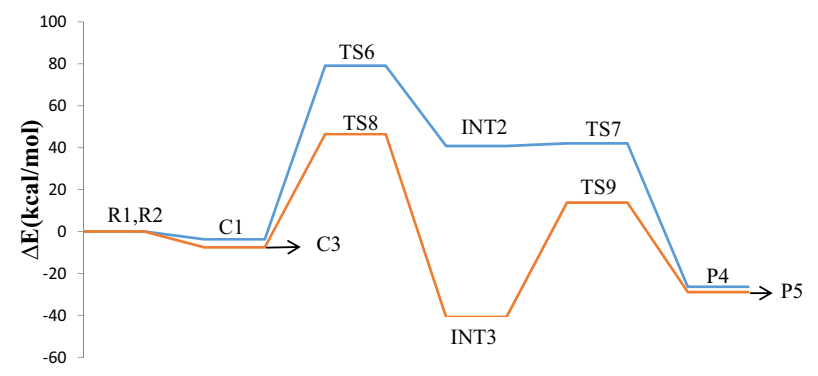

Fig. 4 The calculated energy profile along the proposed routes for the production of the $\mathrm{P} 4$ and $\mathrm{P} 5$ products at the B3LYP/6311++G (3df, 3pd) level of theory

$\left(\mathrm{CH}_{2} \mathrm{O}\right)_{2},\left(\mathrm{CH}_{2} \mathrm{~S}\right)_{2}, \mathrm{CH}_{2} \mathrm{O} / \mathrm{CH}_{2} \mathrm{~S}$. They have optimized all stationary points at the MP2/aug-cc-pVTZ level and several density functional theory (DFT) methods. To obtain more accurate energies, they carried out the single point calculations at the MP2-F12 3C(FIX) and CCSD-F12(T) methods in connection with the aug-cc-pVTZ basis set on the optimized structures of the MP2/aug-cc-pVTZ level. For formaldehyde dimer, they found five minimum structures denoted by I( $\left.C_{5}\right), \|\left(C_{2 h}\right), I I\left(C_{2 h}\right), \operatorname{IV}\left(C_{2 v}\right), V\left(C_{2 v}\right)$. The relative energies of the mentioned structures at the CCSD-F12 (T)/aug-cc-pVTZ level are $-4.58,-3.77,-2.63,-2.54$, $-2.44 \mathrm{kcal} / \mathrm{mol}$, respectively [2]. In our work, the structures $\mathrm{I}\left(\mathrm{C}_{\mathrm{s}}\right), \mathrm{II}\left(\mathrm{C}_{2 \mathrm{~h}}\right)$ are observed with the relative energies of -3.77 and $-3.14 \mathrm{kcal} / \mathrm{mol}$, respectively.

Karpfen studied the minima structures of some dimers such as trans-glyoxal, trans-acrolein, and formaldehyde. He optimized all stationary points at the MP2/aug-cc-pVTZ level and the precise energies computed at the $\operatorname{CCSD}(\mathrm{T}) /$ aug-cc-pVTZ level. For formaldehyde dimer, he found two minimum structures $I\left(C_{s}\right), I\left(C_{2 h}\right)$ same as Dornshuld et al. work. The I $\left(C_{s}\right)$ structure $(-19.7 \mathrm{~kJ} / \mathrm{mol})$ at the $\operatorname{CCSD}(T) /$ aug-cc-pVTZ level is $3.2 \mathrm{~kJ} / \mathrm{mol}$ is more stable than the $\|\left(C_{2 h}\right)(-16.5 \mathrm{~kJ} / \mathrm{mol})$ [29]. This difference in our work is $2.64 \mathrm{~kJ} / \mathrm{mol}$.

Řezać and Hobza considered several dimers to prove that the $\operatorname{CCSD}(T) / C B S$ level has good results in describing noncovalent interactions. In the case of formaldehyde dimer same as other groups, they predicted the structure of $I\left(C_{s}\right)$. The obtained energy for this structure is $-4.55 \mathrm{kcal} / \mathrm{mol}$ [26]. Dolgonos [17] studied the structures I(Cs), II(C2h) at the same 
Fig. 5 Geometries of reactants, products, intermediates, and transition states optimized at the B3LYP level

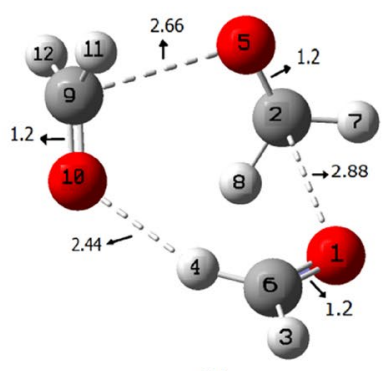

C4

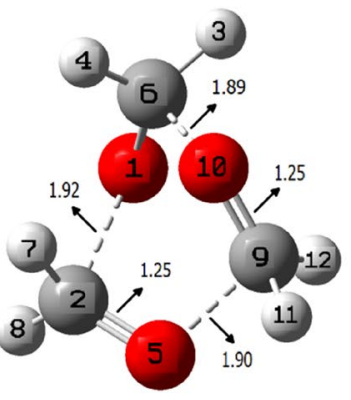

TS10

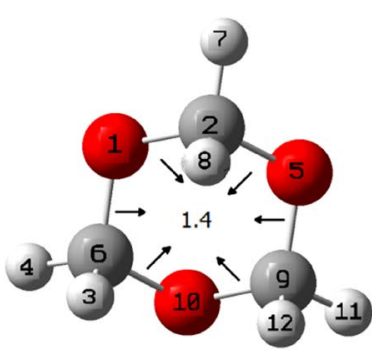

P6
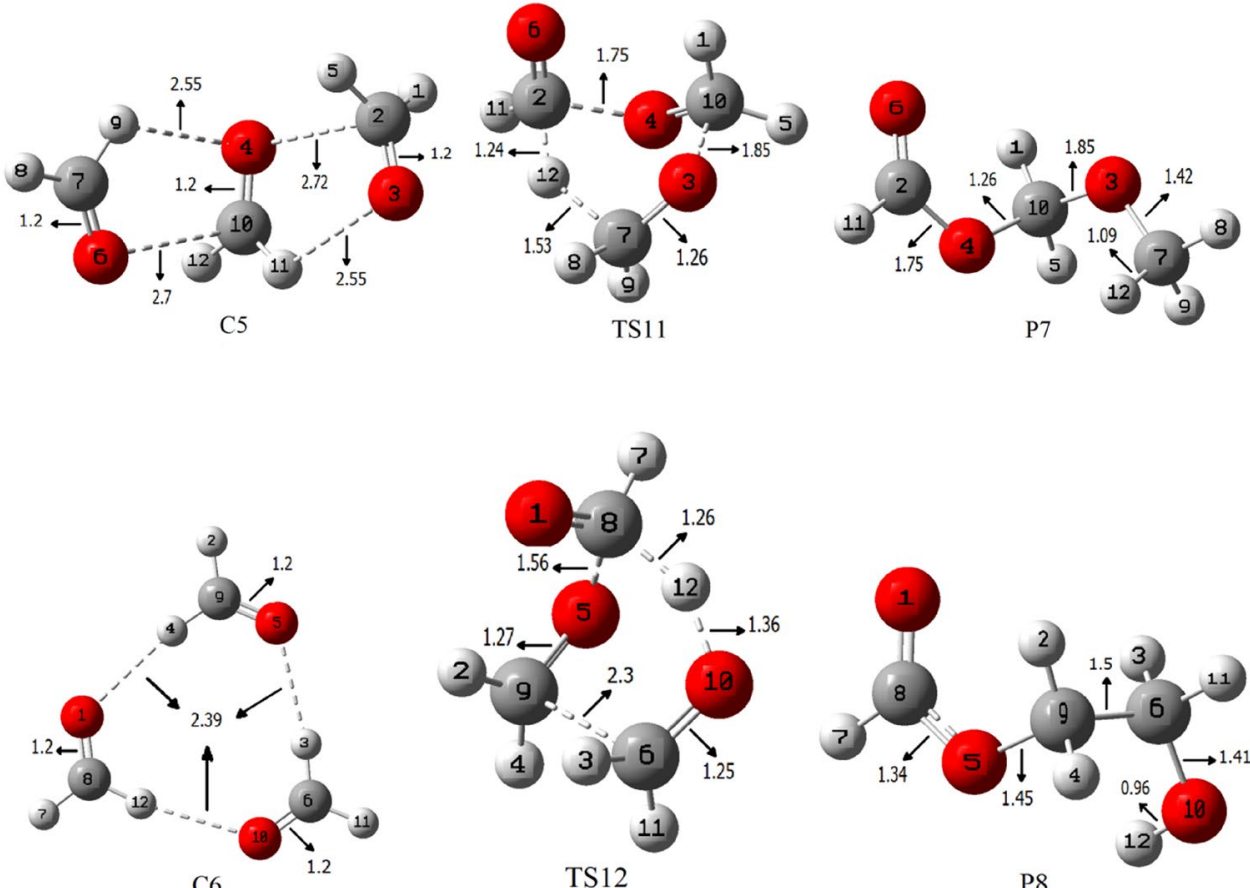

TS 12

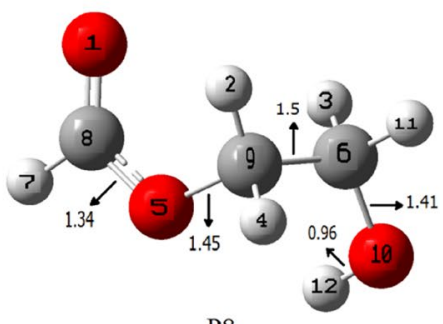

P8

Table 3 The reaction energies, enthalpies, free energies, and entropies $(\mathrm{kcal} / \mathrm{mol})$ are in $298 \mathrm{~K}$ at the B3LYP method

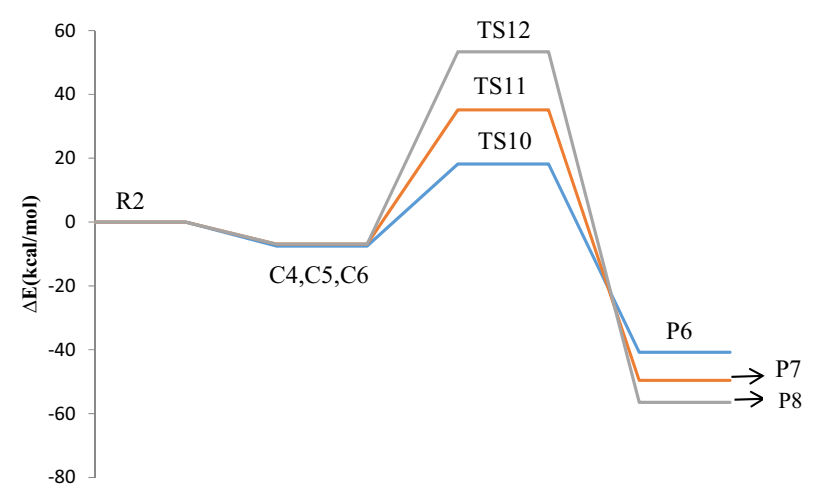

Fig. 6 The calculated energy profile along the proposed routes for the production of $\mathrm{P} 6, \mathrm{P} 7$, and $\mathrm{P} 8$ at the B3LYP/6 311++G (3df, 3pd) level

\begin{tabular}{lllll}
\hline Reaction & $\Delta E^{0}$ & $\Delta H^{0}$ & $\Delta G^{0}$ & $T \Delta S^{0}$ \\
\hline $\mathrm{R} \rightarrow \mathrm{P}$ 1 & 10.06 & 8.01 & 20.80 & -12.79 \\
$\mathrm{R} \rightarrow \mathrm{P} 2$ & -18.44 & -18.2 & -11.79 & -6.41 \\
$\mathrm{R} \rightarrow \mathrm{P} 3$ & -29.90 & -31.34 & -19.57 & -11.77 \\
$\mathrm{R} \rightarrow \mathrm{P} 4$ & -18.97 & -20.48 & -8.53 & -11.95 \\
$\mathrm{R} \rightarrow \mathrm{P} 5$ & -26.22 & -21.14 & -2.51 & -18.63 \\
$\mathrm{R} \rightarrow \mathrm{P} 6$ & -20.01 & 23.90 & 3.20 & -27.10 \\
$\mathrm{R} \rightarrow \mathrm{P} 7$ & -35.83 & -38.52 & -14.76 & -23.76 \\
$\mathrm{R} \rightarrow \mathrm{P} 8$ & -41.03 & -43.79 & -19.89 & -23.90 \\
\hline
\end{tabular}

level of Řezać and Hobza, the calculated relative energies are $-4.48,-3.68 \mathrm{kcal} / \mathrm{mol}$, respectively. The energies of the CCSD(T)/CBS level in Řezać and Hobza study is $0.78 \mathrm{kcal} /$ 
mol for structure $\mathrm{I}\left(\mathrm{C}_{\mathrm{s}}\right)$ and $0.71 \mathrm{kcal} / \mathrm{ml}$ for structure $\mathrm{I}\left(\mathrm{C}_{\mathrm{s}}\right)$ and $0.54 \mathrm{kcal} / \mathrm{ml}$ for structure $\mathrm{II}\left(\mathrm{C}_{2 \mathrm{~h}}\right)$ are lower than our work.

Ohno et al. computed the relative energies of the dimer structures of $\mathrm{I}\left(\mathrm{C}_{\mathrm{s}}\right), \mathrm{II}\left(\mathrm{C}_{2 \mathrm{~h}}\right)$ at several methods such as the MP2, MP2(full), M06-2X, and B3LYP-D3. They showed that the $I I\left(C_{2 h}\right)$ structure is $4.2 \mathrm{~kJ} / \mathrm{mol}$ unstable than the I(Cs) structure at the MP2/aug-cc-pVTZ level. Our result show this unstability is $2.6 \mathrm{kcal} / \mathrm{mol}$ at the CCSD $/ 6-311++\mathrm{g}$ (3df, 3pd) level of theory. The mentioned researchers also calculated the trimer structures of formaldehyde, which were termed by EQ0 [3-0]-EQ9 [3-9] (see Figure 2 and Table 4 in reference [1]). The obtained energies at the B3LYP-D3/aug-cc-pVTZ level show that the EQ1 [3-1] and EQ8 [3-8] were 0.19 and $11.16 \mathrm{~kJ} / \mathrm{mol}$ more unstable than the EQ0 [3-0] structure [1]. The structure of EQ0 [3-0] is similar to the C3 structure, EQ1 [3-1] is similar to the $\mathrm{C} 4$ structure, and EQ8 [3-8] is similar to C6 structure. The structure of EQ0 [3-0], EQ1 [3-1] and EQ8 [3-8] correspond to C3, C4 C6 structure, respectively. Our calculations indicate that the mentioned unstability among these species is 0.00 and $2.63 \mathrm{~kJ} / \mathrm{mol}$, respectively. There is no same structure for the $\mathrm{C} 5$ trimer complex with the other works.

\section{Conclusion}

In this article, a set of binary and ternary complexes of formaldehyde were explored. Due to the nature of electrophilic and nucleophilic reactions of formaldehyde, possible reactions between these compounds were predicted and evaluated. Also, appropriate mechanisms were suggested for their final adducts formation. These mechanisms confirmed the possibility of intermolecular reactions of formaldehyde complexes. Eventually, the catalytic effect of additional formaldehyde molecules was explained.

\section{Compliance with ethical standards}

Conflict of interest The authors declare that they have no conflict of interest.

Ethical approval We certify that the manuscript represents valid work; neither this manuscript nor one with substantially similar content under our authorship has been published or is being considered for publication elsewhere and copies of any closely related manuscripts are enclosed in the manuscript submission. Also, we agree to allow the corresponding author to serve as the primary correspondent with the editorial office and to review and all authors agree to submit of our manuscript in the journal of "SN Applied Sciences".

\section{References}

1. Ohno K, Kodaya Y, Yamakado H (2018) Quantum chemical exploration of formaldehyde clusters $(\mathrm{H} 2 \mathrm{CO}) \mathrm{n}(\mathrm{n}=2-4)$. J Comput Chem 39(20):1498-1507. https://doi.org/10.1002/jcc.25220
2. Van Dornshuld E, Holy CM, Tschumper GS (2014) Homogeneous and heterogeneous noncovalent dimers of formaldehyde and thioformaldehyde: structures, energetics, and vibrational frequencies. J Phys Chem A 118(18):3376-3385. https://doi. org/10.1021/jp502588h

3. Tanaka N, Kusakabe Y, Ito K, Yoshimoto T, Nakamura KT (2002) Crystal structure of formaldehyde dehydrogenase from Pseudomonas putida: the structural origin of the tightly bound cofactor in nicotinoprotein dehydrogenases. J Mol Biol 324(3):519533. https://doi.org/10.1016/S0022-2836(02)01066-5

4. Weng SX, Torrie BH, Powell BM (1989) The crystal structure of formaldehyde. Mol Phys 68(1):25-31. https://doi. org/10.1080/00268978900101941

5. Schneider WG, Bernstein HJ (1956) Molecular association and infra-red spectrum of solid formaldehyde and acetaldehyde. Trans Faraday Soc 52:13-18. https://doi.org/10.1039/TF956 5200013

6. Hu Y, Faham S, Roy R, Adams MW, Rees DC (1999) Formaldehyde ferredoxin oxidoreductase from Pyrococcus furiosus: the $1.85 \AA$ resolution crystal structure and its mechanistic implications. J Mol Biol 286(3):899-914. https://doi.org/10.1006/ jmbi.1998.2488

7. Tyihak E, Bocsi J, Timar F, Racz G, Szende B (2001) Formaldehyde promotes and inhibits the proliferation of cultured tumour and endothelial cells. Cell Prolif 34(3):135-141. https://doi.org/10.1 046/j.1365-2184.2001.00206.x

8. Sutherland BW, Toews J, Kast J (2008) Utility of formaldehyde cross-linking and mass spectrometry in the study of proteinprotein interactions. J Mass Spectrom 43(6):699-715. https:// doi.org/10.1002/jms.1415

9. Liu Y, Liu WQ, Li HY, Yang Y, Cheng S (2007) Hydrogen bonding interaction of formic acid-, formaldehyde-, formylfluoridenitrosyl hydride: theoretical study on the geometries, interaction energies and blue-or red-shifted hydrogen bonds. Chin J Chem 25(1):44-52. https://doi.org/10.1002/cjoc.200790014

10. Maggiora GM, Williams IH (1982) Intermolecular interaction energies from minimal-basis SCF calculations. Interactions pertinent to formaldehyde hydration. J Mol Struct 88(1-2):23-35. https://doi.org/10.1016/0166-1280(82)80104-8

11. Kozmutza C, Evleth EM, Kapuy E (1991) Interaction energy of formaldehyde with ammonia. J Mol Struct 233:139-145. https ://doi.org/10.1016/0166-1280(91)85061-B

12. Dimitrova Y, Peyerimhoff SD (1993) Theoretical study of hydrogen-bonded formaldehyde-water complexes. J Phys Chem 97(49):12731-12736. https://doi.org/10.1021/j100151a017

13. Elstner M, Hobza P, Frauenheim T, Suhai S, Kaxiras E (2001) Hydrogen bonding and stacking interactions of nucleic acid base pairs: a density-functional-theory based treatment. J Chem Phys 114(12):5149-5155. https://doi.org/10.1063/1.1329889

14. Thakur TS, Kirchner MT, Bläser D, Boese R, Desiraju GR (2011) Nature and strength of $\mathrm{C}-\mathrm{H} \cdots \mathrm{O}$ interactions involving formyl hydrogen atoms: computational and experimental studies of small aldehydes. Phys Chem Chem Phys 13(31):14076-14091. https://doi.org/10.1039/COCP02236E

15. Shen XC, Liou XY, Ye LP, Liang H, Wang ZY (2007) Spectroscopic studies on the interaction between human hemoglobin and CdS quantum dots. J Colloid Interface Sci 311(2):400-406. https ://doi.org/10.1016/j.jcis.2007.03.006

16. Deshmukh V, Lee SL, Chaudhari A (2012) Cooperativity effects in linear formaldehyde oligomers using density functional theory calculations. J Mol Model 18(8):3723-3729. https://doi. org/10.1007/s00894-012-1380-9

17. Dolgonos GA (2013) Which isomeric form of formaldehyde dimer is the most stable-a high-level coupled-cluster study. Chem Phys Lett 585:37-41. https://doi.org/10.1016/j.cplet t.2013.08.073 
18. Becke AD (1993) A new mixing of Hartree-Fock and local density-functional theories. J Chem Phys 98(2):1372-1377. https:// doi.org/10.1063/1.464304

19. Lee C, Yang W, Parr RG (1988) Lyp gradient-corrected functional. Phy Rev B 37(2):785-789

20. Frisch MJ et al (2010) Gaussian 09, revision B.01. Gaussian, Inc., Wallingford

21. Chaban GM, Lundell J, Gerber RB (2002) Theoretical study of decomposition pathways for HArF and HKrF. Chem Phys Lett 364(5-6):628-633. https://doi.org/10.1016/S0009 $-2614(02) 01411-2$

22. Curtiss LA, Raghavachari K, Redfern PC, Rassolov V, Pople JA (1998) Gaussian-3 (G3) theory for molecules containing first and second-row atoms. J Chem Phys 109(18):7764-7776. https ://doi.org/10.1063/1.477422

23. Boys SF, Bernardi FD (1970) The calculation of small molecular interactions by the differences of separate total energies. Some procedures with reduced errors. Mol Phys 19(4):553-566. https ://doi.org/10.1080/00268977000101561

24. Biegler-Konig F, Schonbohm J, Derdau R, Bayles D, Bader RFW (2000) AIM 2000, version 1. Bielefeld, Germany

25. Brooks MA, Scott LT (1999) 1,2-shifts of hydrogen atoms in aryl radicals. J Am Chem Soc 121(23):5444-5449. https://doi. org/10.1021/ja984472d
26. Rezac J, Hobza P (2013) Describing noncovalent interactions beyond the common approximations: how accurate is the "gold standard", CCSD (T) at the complete basis set limit? J Chem Theory Comput 9(5):2151-2155. https://doi.org/10.1021/ct400 $057 w$

27. Lovas FJ, Suenram RD, Coudert LH, Blake TA, Grant KJ, Novick SE (1990) The torsional-rotational spectrum and structure of the formaldehyde dimer. J Chem Phys 92(2):891-898. https://doi. org/10.1063/1.458123

28. Andersen J, Voute A, Mihrin D, Heimdal J, Berg RW, Torsson M, Wugt Larsen $\mathrm{R}$ (2017) Probing the global potential energy minimum of $\left(\mathrm{CH}_{2} \mathrm{O}\right)_{2}$ : THz absorption spectrum of $\left(\mathrm{CH}_{2} \mathrm{O}\right)_{2}$ in solid neon and para-hydrogen. J Chem Phys 146(24):244311. https:// doi.org/10.1063/1.4990042

29. Karpfen A (2015) On the potential energy surfaces of dimers formed between trans-glyoxal, trans-acrolein and formaldehyde. Comput Theor Chem 1061:60-71. https://doi. org/10.1016/j.comptc.2015.03.001

Publisher's Note Springer Nature remains neutral with regard to jurisdictional claims in published maps and institutional affiliations. 